\title{
O DISCURSO DA DIPLOMACIA AMBIENTAL E AS INTERAÇÕES COM O CONTEXTO DA CONTEMPORANEIDADE: uma análise das intercorrências da cooperação internacional
}

\begin{abstract}
ARAUJO, Paulo Ricardo da Rocha*
\section{Resumo}

Este artigo trata da questão da Diplomacia Ambiental e suas interações com o contexto da contemporaneidade desde a abordagem da análise preliminar dos discursos que têm caracterizado essa prática. Toma-se com exemplo de cooperação internacional, bem como as intercorrências do discurso, o caso das papeleiras no Uruguai que têm apresentado os elementos que uma cena enunciativa demanda. Isso porque, a análise de discurso envolve reflexões sobre as condições de produção dos textos analisados, isto é, da própria realidade na qual estão imersos e o processo histórico, cultural e ideológico nos quais estão situados. Sob a segunda ótica, este artigo retoma Orlandi (2002) ao enfatizar que na análise do discurso deve-se evidenciar a compreensão do que a textualização do político, a simbolização das relações de poder, o modo de historicização dos sentidos, o modo de existência dos discursos no sujeito, na sociedade e na história. Seria, para essa autora, uma forma apropriada para desvelar os mecanismos de dominação, por exemplo, escondidos sob a linguagem.
\end{abstract}

Palavras-chave: Diplomacia Ambiental. Ambientalismo. Discurso. Legitimidade. Cooperação Internacional.

\begin{abstract}
This article deals with Environmental Diplomacy and its interactions with the context of contemporaneity since a preliminary analysis of discourses that have characterized this practice. As an example of international cooperation and of the interoccurencies of the discourse is the case of cellulose plants in Uruguay. Discourse analysis involves understanding of historical process, cultural and ideological context in which the analysed texts have been socially constructed. Orlandi(2002) stresses the importance of the contextualization of the political, as well as of the symbols indicating power relationships, the way meanings become history, and the way the discourses interfers upon actors, society and history. It woul be, for that author, an appropriate way to unveil the mechanisms of power and domination, for instance, within language.
\end{abstract}

*Professor-Doutor Pesquisador do Programa de Pós-Graduação Stricto Sensu em Planejamento e Gestão Ambiental da Universidade Católica de Brasília, Brasília/DF. E-mail: pdarocha@pos.ucb.br, pauloricardorar@gmai.com 
Key words: Environmental Diplomacy. Environmentalism. Discourse. Legitimacy. International Cooperation.

\section{Introdução}

"Quem fala? Quem, no conjunto de todos os indivíduos falantes, tem a autoridade de exercer esta espécie de linguagem? (...)A fala médica não pode vir de qualquer um, seu valor, sua eficácia, seus próprios poderes terapêuticos e, de forma geral, sua existência como fala médica não são indissociáveis do personagem estatutariamente definido que tem o direito de articula-la" (FOUCAULT, M. A arqueologia do saber. p. 68)

Parte-se, neste artigo, do princípio de que, na perspectiva discursiva, os sentidos sempre podem ser outros. Há, entretanto, em todo discurso, uma relação tensa entre o que é estabilizado e o que é sujeito a equívoco, entre o mesmo e o diferente, entre a paráfrase e a polissemia. Há um trabalho da interpretação que se fixa. Há o desejo de um mundo semanticamente normal em todo sujeito que faz com que haja um fechamento dos sentidos.

O discurso da diplomacia ambiental tende para este fechamento e é isto que pretende-se compreender neste artigo. Os exemplos que o contexto da contemporaneidade apontam e podem ser localizados desde a mundialização da indústria farmacêutica (Chesnais), dos diretos humanos como direito dos mais vulneráveis (Aids x Malária), no sentido em bioética, biodireito, da propriedade intelectual/ patentes/ domesticação da natureza pelas populações autóctones; da privatização da água (os barões da água, multinacionais que comercializam, por exemplo Montsanto) e o híperagronegócio (pela tecnologia e redimensionamento da vocação da agricultura, além de outros assuntos, temos aí uma padronização/mundialização/globalização objetivando mercado de gostos e sabores); na realidade, o agronegócio reconfigura a vocação da terra cultivável com a agroenergia que passou a ser um fator importante para o crescimento da agricultura nos últimos 3 anos (a partir de 2003) tendo o etanol como projeto-piloto. Mais recentemente, a bioenergia anima e muda o agronegócio - procura mundial por substitutos do petróleo caro beneficia campo brasileiro, principalmente cana-de-açúcar, soja e milho. Constituem, ainda, parte significativa do discurso da diplomacia ambiental o lugar ocupado pelo ao caráter continental do Brasil, a abundância de água e sol e, com isso, a extensão de terras cultiváveis aliada à tecnologia na agricultura conduz o pais à celeiro energético junto com USA, China, sobretudo.

Ocorre que, desde a laicização do Estado-Nação e, em conseqüência, das Relações multilaterais Internacionais haveria uma 'sacralização' do político - mesmo no contexto da contemporaneidade - que tem sido trazida pelo reconhecimento (vital) de limites de sustentabilidade aos projetos de desenvolvimento como também pela aceitação/prática/reconhecimento da "biodiversidade cultural" na agenda político-ambiental em termos mundiais. Assim, o sentido de fechamento do discurso da Diplomacia Ambiental parece intermediado pela dialógica da complexidade (Morin, 1990). 
Seria esse movimento dialógico a ser interpretado, desde o discurso ambiental sobre questões que se mostram decisivas das relações entre os países - atitudes interpretativas diferentes quanto à sustentabilidade ambiental imbricadas em opções estratégicas de uso/apropriação dos recursos naturais, no caso, a água do rio Uruguai, contíguo entre o Uruguai e a Argentina, ou dos recursos energéticos e sua origem (não-fósseis e limpas). Especificamente, neste artigo, seria o caso das indústrias multinacionais de celulose em processo de instalação em Fray Bentos - margem uruguaia do Rio Uruguai, rio contíguo entre esse país e a Argentina - e suas decorrências como a instalação da Assembléia Ambientalista de Gualeguaychú (cidade situada ao longo da margem argentina), o foco da interpretação dos discursos da Diplomacia quando revestida do cunho ambiental. Sistematizado desse modo, as análises pretendem refletir desde os discursos sobre os elementos teóricos e práticos que fundamentam a Diplomacia Ambiental. Isso porque, algumas questões são suscitadas como: qual seria a concepção de estado-nação que os discursos deixam transparecer? quais seriam os delineamentos quanto à configuração das Relações Internacionais que podem ser depreendidas desde esses discursos?

\section{Metodologia}

A análise de discurso, como metodologia, procura assim determinar as condições de produção dos textos e os efeitos de sentidos produzidos: quem diz, para quem, onde e quando. Fazendo sua reflexão de Baktin (2004), ignorar a natureza dos discursos é o mesmo que apagar a ligação entre a linguagem e a vida ou negar a relação entre língua e ideologia (Orlandi, 2002). Na concepção de Maingueneau (1997), integrante da escola francesa de Análise do discurso, sua perspectiva teórica guarda uma estreita relação com o conceito de 'formação discursiva', a partir do pensamento de Foucault (2002) que se vale desse termo para designar um conjunto de enunciados que podem ser associados a um mesmo sistema de regras historicamente determinadas. Assim, define-se 'discurso', como o conjunto de enunciados na medida em que revele na prática uma formação discursiva. Voltando às idéias de Baktin e Maingueneau, o sentido do discurso relaciona-se ao gênero dos discursos presentes nos espaços sociais, sendo na manifestação de suas diferenças dentro dessas realidades que os discursos devem ser analisados: lugar social do qual emerge, canal por onde é veiculado, tipo de difusão que implica, respostas que suscita e efeitos produzidos. Maingueneau (1997) observa a infinita possibilidade de gêneros discursivos, cabendo ao analista defini-lo em função de seus objetivos e dos recortes genéricos que lhes parecem pertinentes. Entretanto, para esse autor, é relevante considerar que "a cada gênero, como toda instituição constrói o tempo-espaço de sua legitimação." (Maingueneau, 1997, p. 36). Por sua vez, Baktin apresenta o gênero de discurso como parte do ambiente social, numa interação que ora produz coincidências, ora produz ajustes: "cada época e cada grupo social têm o seu repertório de gêneros discursivos, que funciona como um espelho que reflete e refrata a realidade." (Baktin, 2003, p. 14).

Uma vez que para a análise do discurso o que funciona não são os locutores empíricos, nem as situações físicas, mas a sua projeção, um empresário, por exemplo, pode falar da posição do ministro das Relações Interacionais de um dado país. São essas posições que interessam ao analista de discurso. Analisa-se, ainda, a estruturação dos textos e seus mecanismos de argumentação(as escalas argumentativas, por exemplo). Se dizemos "O Uruguai adota uma atitude tecnologicamente otimista" estamos tomando uma perspectiva 
diferente da que tomaríamos se disséssemos "A Argentina adota uma posição ecologista radical desumanizada". Todos esses mecanismos nos dão indicações sobre os efeitos de sentidos, a ideologia etc.

Em uma primeira fase, procura-se apenas observar os fatos mais salientes em relação aos discursos analisados. Em seguida, procura-se estabelecer a relação entre o dito e o não-dito(o silêncio) e os múltiplos efeitos de sentidos de um mesmo conceito(ou noção) em diferentes co-textos(ou contextos). Os tipos de materiais não chegam a influir em relação às formas do discurso da diplomacia ambiental. Os componentes citados acima estão presentes, de maneiras específicas, mas presentes, em todos os tipos de materiais.

Como era de se esperar, quanto aos temas, há menos investimento em estruturas e processos/relações, um pouco mais de insistência nas relações sociedade-natureza e bem mais tematizado é o enfoque sobre as três esferas (conceitos, valores e participação/cidadania). Considerando que um acarreta o outro, costuma-se concentrar o debate na participação em detrimento, por exemplo, das análises sobre as estruturas.

Quanto à organização textual do material, o esquema ideal encontrado - em poucas publicações - segue o modelo: história, descrição, efeitos, reflexão e proposta de soluções. Este esquema, no entanto, não é muito freqüente. É alterado seja pela eliminação da história, seja pela exacerbação dos efeitos (nem sempre bem definidos); seja pela substituição da reflexão pela "conscientização" e pela substituição da proposta de soluções por um discurso moralista e, em geral, de culpabilização. Daí para o deslize de sentidos turístico, demagógico, sensacionalista, imperativo, instrucional ou "sacralização" (seja do político ou do meio ambiente).

\section{Entre o discurso "sobre" e o discurso "da" diplomacia ambiental}

Esta é uma separação nítida no conjunto de textos. Isso não significa que há textos puramente "sobre" diplomacia ambiental e outros só "de" diplomacia ambiental. Mas há grande parte dos textos que não chegam a praticar a interpretação da diplomacia ambiental. São sempre "sobre", e só um pouco "de".

Esta é uma característica que faz com que haja uma produção enorme de "preâmbulos". Isso seria desfavorável àqueles que pretendem atingir a memória discursiva, os fatores constituintes da diplomacia ambiental. Fica-se sempre nas 'ante-salas'. Isto dá as características de um discurso fortemente ritualizado e que produz o efeito dos "iniciados", o efeito da exclusão. Em consequência, leva ao contrário da propalada "conscientização", isto é, à rejeição. Entre, de um lado, o discurso dos iniciados (de difícil acesso) e, de outro, o imediatismo de uma ação apenas reativa, o que fica como perda é o que se devia saber para se saber a questão ambiental: parecem, com isso, gerar o fenômeno do 'raciocínio circular': discursos que se autoalimentam sem deixar espaço para a reflexão real.

\section{Análise dos dados}

Há duas críticas a serem feitas a esses materiais quanto a suas propriedades: a. o discurso da catástrofe (quando não apocalíptico), e b. o imediatismo. A catástrofe produz 
uma argumentação dividida entre: a. Argumentos de perdição (o sistema é um monstro) e b. Argumentos de salvação (nostalgia, desembocando sobre o óbvio, e mobilização de preconceitos). O imediatismo desloca para o "comportamento humano" o que é "fato de um processo". Daí o moralismo, os argumentos de árbitros sobre o futuro da humanidade. O que leva bem cedo a um discurso religioso, catequético. Em relação a essas características, do outro lado, o outro discurso é o iluminista, que investe tudo na racionalidade. E isto também se verifica nos textos analisados. Parece não haver a integração do homem no novo fato que se anuncia. Nessa opção pelo Iluminismo - que despreza todos esses aspectos da relação com o saber - como fica o político? E a relação sociedade/história?

A questão da cidadania nem sempre aparece fato esse que parece estar relacionado, como se pretende demonstrar, mais adiante, à contradição que afeta a relação entre o social e o natural no discurso ecológico.

A cidadania tem muitos sentidos. Fundamentalmente põe em pauta a relação entre direitos e deveres do sujeito face ao Estado e ao político. O que observamos é que, fora as posições de órgãos governamentais ou dos que mobilizam a questão política mais explicitamente, a referência à cidadania vem dita, em grande parte dos textos, por um discurso neo-liberal em que o locutor principal é a Empresa (neste caso, especificamente, as transnacinais). Daí que o cidadão é antes o consumidor do que o habitante do país com seus direitos e deveres. Não se trata do direito político.

Raramente se divulgam as leis e, como sabemos, o discurso jurídico é constitutivo, em primeira instância, da cidadania. Sua mobilização adequada poderia ser um dos elementos importantes na construção da consciência da cidadania. Fica-se mais no "prático", no "imediato": serviço de utilidade pública, de publicidade, de auto-promoção, de campanha política etc. Há alguns casos, raros mas interessantes, em que a cidadania é bem colocada. Por exemplo, em um Manual, pela conversa, estabelece-se a relação entre a experiência e o conhecimento, a responsabilidade do indivíduo e a sua ligação com o Estado. É um bom exemplo de argumentação adequada. Na maior parte das vezes, entretanto, se fala da relação entre o homem e a natureza em termos de formação de uma consciência ecológica e se chega a usar a referência à preservação ambiental para se falar de cidadania sem, no entanto, preencher de sentido a cidadania em sua dimensão histórica e social. Fala-se da participação do "jovem" mas não se menciona sequer a participação do Estado. Por sua vez, os textos jornalísticos, cientificamente corretos, quando falam da relação entre seres vivos excluem o homem(porque excluem o social) e só fazem intervir o ser humano para falar do que está sendo "depredado" etc, quando o equilíbrio é rompido. Esta é uma pista interessante. Quando o social aparece, aparece o mal. O que mostra que, mesmo que se diga o contrário, há uma oposição entre natureza e sociedade, nesses discursos. Ou ela é apagada, ou é negada, ou é atacada.

Mais específicamente, há uma formulação que mostra bem o processo de significação apontado: "sabe-se a relação direta que existe entre a degradação ambiental e a degradação social, mas não optamos por ficar omissos e de braços cruzados". O que significa este "mas" aí? 
O pressuposto é de que nada se pode fazer pelo social "mas" nem por isso se deva ficar omisso quanto ao ambiente. Esta é, creio, a contradição fundamental que atravessa todo esse discurso. Junta-se a isso a des-historicização, a des-culturação(o índio é um ser natural ecológico, o homem não é cultural). Como se quer, então, se politizar? Ou a questão da cidadania não é uma questão política, e, logo, histórica e social?

Nessa perspectiva, não se trata de "proteger" a natureza. Melhor seria "proteger" o homem. Mas tampouco esta é a posição mais interessante. Trata-se de não evitar a necessidade da transformação da natureza pelo homem. Isto é a história: essa relação necessária e transformadora do homem com a natureza e com a sociedade. Ser críticos e conseqüentes em relação a esta questão é, pois, não evitar a história e não procurar apagar o social como constitutivo dessas relações. O que este discurso faz é esvaziar o social como estruturante e ficar em seus efeitos, através do deslize para o indivíduo. Se algo corre mal, se fica reduzido a uma ação policialesca: proíbe-se, acusa-se etc. Nesse sentido, há uma posição interessante entre biólogos que escapa desse sentido: "Já que o homem interveio para causar danos, ele deve continuar intervindo para reparar estes danos"(Leitão Filho,1996).

Um outro aspecto importante que encontramos em nossa análise é que não se explora a diferença entre as leis "da" natureza e as leis "sobre" a natureza. Só o homem pode fazer leis sobre a natureza. Aí está mais uma das dimensões do caráter jurídicopolítico, importante a ser explorado na relação homem/natureza [600/BRA. C/6ed./e.2].

Estes pressupostos vão produzindo uma característica marcante da formação discursiva da diplomacia ambiental, constituída por uma certa relação com a ideologia. Apesar de todas as boas intenções. Essa característica define um lugar peculiar para esse discurso que é o da dupla negação: ele nega o não (não é verdade que não se pode fazer algo pelo meio ambiente). Daí sua extrema fragilidade, pois ele não afirma algo diretamente. Ao negar a negação, ele não discerne, joga com um "tudo" indefinido. Daí a impressão de onipotência e, ao mesmo tempo, a vaguidade, pela indefinição: "A ecologia é a gente fazer algo pelo meio ambiente..." (sic)

$\mathrm{Na}$ forma discursiva, isto aparece em uma fala que retorna ao já dito (o estereótipo: "melhor qualidade de vida", "exercício pleno da cidadania", "os seres que participam do equilíbrio ecológico daquele ambiente" etc) e que imobiliza acenando com a catástrofe pela denegação (não deixe que o homem destrua...). Fazendo com que o sentido funcione pela evidência (efeito do já-dito). É preciso desarticular esse discurso para que ele se abra, para que ele encontre um interlocutor mais real e mais variado. Abrir tanto em relação aos termos e conceitos já excessivamente cristalizados e em relação à estruturação do texto. Necessário se faz, ainda, um certo distanciamento do esquematismo. Pois, desse ponto de vista, de sua estruturação e da argumentação, os textos são previsíveis demais.

Mesmo os textos jornalísticos e os literários se ressentem de esquematismo e do que poderia ser definido como "homogeneidade" ideológica. Os mecanismos das narrativas tornam esses problemas até mais visíveis. As metáforas (simulação, em animais, de panfletarismo, por exemplo), ao invés de abrirem para o possível, para deixarem entrar a história do leitor, barram, pelo retorno a paráfrases. Mais uma vez, privilegiam-se os 
comportamentos e não a prática, de um homem (indivíduo) representado, em sua dimensão pragmática, como animal em interação e não, como devia ser, como ser social sujeito a determinações históricas e também capaz de movimentar essa história, de transformar relações.

Um outro aspecto, finalmente, que contribui para o que estamos chamando "fechamento" desse discurso é o fato de que na realidade não há apenas "migração" de sentidos de uns para os outros, o que é, de algum modo, inevitável. O que há é um processo pelo qual os sentidos são, por assim dizer, "transportados" de um texto para o outro (daí o efeito de estereotipia). Ora, do ponto de vista discursivo, sabemos que embora "pareça" que os sentidos estariam acabados, prontos e completos, eles estão se fazendo o tempo todo. Assim, pode-se perguntar: haveria um sentido privilegiado para "ecologia"? Qual é a capacidade do discurso da diplomacia ambiental de deixar-se trabalhar pelos sentidos possíveis de "ecologia"?

Chega-se, enfim à crítica mais conseqüente ao material analisado e que se configura como discurso de diplomacia ambiental: é um discurso que se inscreve no "comportamentalismo" com todos os inconvenientes dessa posição e em seus efeitos. Dentre esses, destaca-se seu efeito moralista, doutrinário e autoritário (sob o modo paternalista ou iluminista) Note-se que um amplo espectro de movimentos sociais comprometidos com a temática ambiental - de ambientalistas messiânicos a neocapitalistas verdes, de ONGs contemporâneas a instituições supranacionais ecologizadas - passam a atuar como grupos de pressão. No sentido de tornar efetivas suas reivindicações, esses movimentos necessitam continuar atuais e participativos, forjar e adaptar-se a distintas alianças político-estratégicas com o poder, objetivando, principalmente, a assistência financeira.

Por sua vez, a disponibilização e alocação de recursos - e a transparência em processos de gestão e aplicação de financiamento - tenderiam a dar espaço de vida, de militância e de trabalho a movimentos que não dispõem de visibilidade midiática internacional. A visibilidade global - só tornando-se efetiva com o interesse e aval desses meios de comunicação - proporciona poder de persuasão e favorece parcerias estratégicas entre grupos ambientalistas e outros atores internacionais. Parcerias pragmáticas concorrenciais de mercado e não, necessariamente, caracterizada por tessituras ideológicas.

Isso faz crer que o input é dado pela "ameaça" (a destruição do mundo em que vivemos), o processamento vem pelo "julgamento"(você é culpado) e o output é o automatismo de uma ação que re-coloca o indivíduo(não há historicização) como mero "usuário"(consumidor). Enquanto discurso comportamental, é uma fala que desconhece aspectos cruciais da constituição dos sentidos, da história, dos sujeitos. Daí o trabalho de seus equívocos: fala-se de um número abrangente de fatores mas, de fato, restringem-se ao pragmatismo de seus personagens.

Isso não ocorreria "impensadamente": esta é ainda uma das maneiras de elidir o irracional, o imaginário, o político, necessariamente presentes na ação humana. Gesto de interpretação que, não admitindo do que é feito, por isso mesmo não atravessa os efeitos que produz. 
Cabe situar que essa cena enunciativa tem início com a apropriação de idéias inovadoras dos anos 1960/70 que desafiavam o status quo caracterizado pelo consumo, industrialismo extrativista e colonização cultural, entre outros, constituindo o sentido inicial da constituição de uma prática da Diplomacia Ambiental. Dessa prática, faz parte a crítica que emana da análise das duas ideologias dominantes do século XX: o capitalismo e comunismo apresentando-se como provedores do prazer material através de um desenvolvimento antropocêntrico e excludente com os seus respectivos países-satélites.

A atual realidade da profana peregrinação - e embates - na competição pelo dinheiro e pelo crédito vem dessacralizando purismos messiânicos que orientavam o discurso de alguns movimentos ambientalistas dos anos 1960/1970. Tal dessacralização como essa suposta democratização na alocação de crédito desafia práticas de pensar monolíticas pelo controle do discurso ambiental.

Como exemplo de novos tempos onde a conscientização ambiental é forjada pela vocação social e embates de movimentos sociais de países não economicamente hegemônicos, pode ser citado o conjunto de contribuintes - vítimas, ou não, de doenças relacionadas ao tabagismo. Esses contestam tanto os custos preventivos e curativos desta epidemia (expressão da Secretária Geral da Organização Mundial da Saúde, Sra. Brundtland em seu discurso de posse, em 11 de maio de 1998), quanto o incentivo fiscal que financia as multinacionais do fumo pela isenção de impostos. Contesta-se, desse modo, o uso do dinheiro público para fins privados.

Um outro exemplo desses novos contornos decorre da experiência dos moradores do bairro Recanto dos Pássaro: vítimas de área contaminada com produtos agrotóxicos organoclorados de antiga fábrica da multinacional Shell - em Paulínea/SP, a $140 \mathrm{~km}$ da cidade de São Paulo - organizaram-se para fazer valer seus direitos enquanto a Resolução 237/97 do CONAMA (Comissão Nacional de Meio Ambiente) estabelece que as atividades de impacto local são de responsabilidade dos municípios.

Desde a Conferência em Kioto (1997), busca-se o delineamento de ações objetivando mitigar os efeitos negativos de uma tendência de aquecimento global da atmosfera. Esse parece ser um novo espaço geopolítico da Diplomacia Ambiental que poderia ser caracterizado pelos discursos dos atores economicamente hegemônicos no controle do mercado de percentuais de reduções entre países. Ao mesmo tempo, houve a intensificação do comércio ilegal de material e dejetos radiativos marcado pelo final da guerra fria nos anos oitenta. Nesse sentido, talvez futurista fosse o surgimento de bolsas de valores e de mercados de capitais em função do comércio de percentuais de reduções entre países.

\section{Primeiras Conclusões}

Inferem-se, dessas primeiras análises, a percepção de que não se deve aceitar a separação entre forma e conteúdo, na linguagem ('o como se diz já é o que se diz'). Isso significaria que uma análise do discurso a partir do processo de constituição do campo da "Diplomacia Ambiental" tendo como elementos teórico-práticos o caso das indústrias multinacionais de celulose no Uruguai, por exemplo, deve considerar suas decorrências como a Assembléia Ambientalista de Gualeguaychú (na Argentina), bem como a crise 
paradigmática que os atores hegemônicos (estados-nação, movimentos ambientalistas de cunho internacional) concomitantemente aos atores considerados historicamente como periféricos - indígenas e comunidades locais, entre outros - que representam no cenário de constituição do 'campo de forças' para a compreensão/explicação do discurso da Diplomacia Ambiental.

A desconsideração desses fatores resulta, pelo menos, em dois riscos complementares: de um lado, o de adiar a experiência, ou, de outro, cair no ativismo, no imediatismo. Tendo em conta que tanto a procrastinação de qualquer ação como o açodamento se apresentam com favoráveis ao exercício hegemônico de um dado discurso, essas primeiras análises intentam o desvelamento de uma prática de Diplomacia Ambiental anacrônica.

\section{Referências Bibliográficas}

ARAUJO, P. R. da. O novo estatuto do meio ambiente na prática empresarial mundializada: uma análise preliminar sobre a logística reversa. Revista Gaia Scientia, abril, 2007, pp. 20-38

CHESNAIS, F. A mundialização do Capital. São Paulo Xamã, 1996.

MAINGUENEAU, D. Análise de discurso: a questão dos fundamentos. Cadernos de Estudos de Linguagem. Campinas, SP: (19): jul/set. 1990.

Unicamp, 1989.

Novas tendências em Análise do discurso. Campinas: Pontes/Ed. da

MORIN, E. O problema epistemológico da complexidade. Portugal: Publicações EuroAmericanas, 1990

OMAN, Charles. Globalisation et régionalisation: Quels enjeux pour les pays en développement? Paris: OCDE, 1994. 116 p.

ORLANDI, E. P. Discurso, Imaginário Social e Conhecimento. Em aberto. Brasília (14) 61, jan/mar, 1994, p.53-59.

PORTO-GONSALVES, C. W. O desafio ambiental. Rio de Janeiro-RJ: Afiliada. 2004

VIOLA, E. Confronto e legitimação (1970 a 1990). In: SVIRSKY, E.; CAPOBIANCO, J. P.R. (orgs). Ambientalismo no Brasil: passado, presente e futuro. São Paulo: Instituto Socioambiental. 1997. p 27-36.

WALlACE, A. Revitalization movements. American Anthropologist, v. 58, p. 264-81, 1956 